\title{
NDM-producing enterobacteriaceae strains among hospital in brasília, brazil
}

\begin{abstract}
Carbapenem-resistant Enterobacteriaceae (CRE) strains have spread worldwide frequently driven by clonal spread. Additionally, plasmid-borne carbapenemase genes $\left(b l a_{\mathrm{KPC}}\right.$ and $\left.b l a_{\mathrm{NDM}}\right)$ have broadened the variability of species expressing resistance to carbapenems. This study aimed to characterize the susceptibility profile and bla genes in CRE strains recovered between 2012 and early 2014 in hospitals in Brasília, Brazil. Eighty eight CRE strains recovered from 19 medical settings were analyzed. Klebsiella pneumoniae positive for $b l a_{\mathrm{KPC}}$ accounted for the most of the CRE isolates ( $\left.\mathrm{n}=47 ; 53.4 \%\right)$. Seven $b l a_{\mathrm{NDM}}$-positive strains (including K. pneumonia, $\mathrm{n}=4$; Proteus mirabilis, $\mathrm{n}=1$; Escherichia coli, $\mathrm{n}=1$; and Providencia rettgeri, $\mathrm{n}=1$ ) were recovered from patients in six hospitals. The first detected $b l a_{\mathrm{NDM}-1}$-positive strain was P. rettigeri. Thereafter, $b l a_{\mathrm{NDM}-1}$-positive $K$. pneumoniae strains showing indistinguishable Random Amplified Polymorphic DNA (RAPD) profiles were recovered in three hospitals. The susceptibility profile of $b l a_{\mathrm{NDM}-1}-$ positive $K$. pneumoniae strains was commonly restricted to amikacin, aztreonam and tigecycline. These dates highlighted the emergence of bla $a_{\text {ma- }}$-positive $K$. pneumonia strains marked by a single RAPD type among hospitals in Brasília, Brazil.
\end{abstract}

Keywords: ndm-producing strains, carbapenemase, klebsiella pneumonia, metallo- $\beta$ lactamase
Volume 3 Issue 2 - 2016

\author{
Celio Faria-Junior ${ }^{*}$, Lilian de Oliveira \\ Rodrigues', James Oki de Carvalho', Octavio \\ Luiz Franco ${ }^{2}$,Alex Leite Pereira ${ }^{3}$ and Brasília \\ Study Group on Bacterial Resistance \\ 'Núcleo de Bacteriologia, Laboratório Central de Saúde Pública \\ do Distrito Federal, Brazil \\ ${ }^{2}$ Centro de Análises Proteômicas e Bioquímicas, Universidade \\ Católica de Brasília, Brazil \\ ${ }^{3}$ Faculdade de Ceilândia, Universidade de Brasília, Brazil
}

\section{Correspondence: Celio de Faria Junior, Núcleo de} Bacteriologia, Laboratório Central de Saúde Pública do Distrito Federal, SGAN quadra 60I, lotes O/P, Asa Norte, CEP 70830 010, Brasília, Brazil,Tel +55-61-3321-0774,

Email celiobioquimico@hotmail.com

Received: September 13,2015 | Published: January 29, 2016

\section{Introduction}

The resistance to carbapenems has become a serious world public health issue since the early 2000 's. ${ }^{1}$ In that time, the world spread of Klebsiella pneumoniae carbapenemase (KPC)-producing strains was supported by the predominance of a well-adapted clone of $K$. pneumoniae (ST258) among hospitals around the world. Moreover, the $b l a_{\mathrm{KPC}}$ gene became easily mobilized by conjugative plasmids among Enterobacteria species. ${ }^{2}$ NDM-1 (New Delhi metallo- $\beta$ lactamase-1) is the most recently discovered molecular class B $\beta$-lactamase encoded on transferable, plasmid-borne genes $\left(b l a_{\mathrm{NDM}}\right){ }^{3}$ The hydrolysis mechanism of NDM relies on the interactions between $\beta$-lactam molecules and zinc ions in the enzyme's active site. Therefore, NDM enzymes are inhibited by zinc-chelating agents such as EDTA. ${ }^{4} \mathrm{NDM}$ can hydrolyze all $\beta$-lactam antibiotics (penicillins, cephalosporins and carbapenems), excepting monobactams. ${ }^{3}$ Additionally, most NDM-positive strains are broadly resistant to other antibiotic classes, and carry a wide diversity of resistance mechanisms against other antibiotics, such as aminoglycosides and fluoroquinolones, rendering these strains extremely resistant to the available treatments. ${ }^{1}$ NDM-1 was first described in K. pneumoniae and Escherichia coli strains isolated in Sweden in 2008 from an Indian patient who had been transferred from a hospital in New Delhi, India. ${ }^{5}$ Nowadays, NDM has also been detected in a broad variety of other Enterobacteriaceae species including $K$. oxytoca, Proteus mirabilis, Enterobacter cloacae, Citrobacter freundii and Providencia spp as well as in aerobic bacilli such as Pseudomonas spp. and Stenotrophomonas spp. ${ }^{3}$ This wide distribution of the $b l a_{\mathrm{NDM}}$ gene reflects its association with promiscuous plasmids. ${ }^{6}$ Regardless the purposes, whether medical or otherwise, international travels have played a significant role in the dissemination of NDM producers, given that, most of the first reports on NDM-positive strains were epidemiologically linked to travels to Indian and Pakistani regions.? In Brazil, the first NDM-producing strain was isolated in 2013 in the South region state, Rio Grande do Sul. ${ }^{8}$ Beside $b l a_{\mathrm{KPC}}$ and $b l a_{\mathrm{NDM}}$, other carbapenemase genes, such as $b l a_{\mathrm{VIM}}, b l a_{\mathrm{IMP}}$ and $b l a_{\mathrm{OXA}-48}$, have been reported in Enterobacteria world-wide, including in Brazil. However, these carbapenemase genes have not been associated with large spreads or epidemic events. ${ }^{9}$

The aim of this study was to define the profile of carbapenemase genes in CRE strains assessing whether NDM-producing strains have reached hospitals in Brasília, the federal capital of Brazil. Moreover, the study evaluated the role of bacterial clones in spreading of $b l a_{\mathrm{NDM}}$ among hospital.

\section{Materials and methods}

From 2012 to 2014, a regional surveillance program was conducted by the Public Health Laboratory (LACEN-DF) in order to assess carbapenem resistance in Enterobacteriaceae isolates recovered from hospitals in Brasília. We have identified 88 carbapenem-resistant Enterobacteriaceae (CRE) strains recovered from patients attended in nineteen medical centers. Identification and antimicrobial susceptibility tests were accomplished using the MicroScan WalkAway ${ }^{\mathrm{TM}}$ system (Dade Behring, USA) and Vitek MS system (Matrix-assisted laser desorption ionization-time of flight mass spectrometry - MALDITOF MS system - BioMerieux) in accordance to the manufacturer's instructions. In order to assess the clinical susceptibility of bacterial isolates, in vitro antibiogram test results were interpreted in accordance to the breakpoints established by the Clinical and Laboratory Standards Institute (CLSI) document published in January 2014. The production of carbapenemase was tested using the modified 
Hodge Test (MHT) employing ertapenem disk adsorbed with $10 \mu \mathrm{g}$ of the antibiotic as described by CLSI. ${ }^{10}$ Metallo- $\beta$-lactamase production was tested with carbapenem-containing disks $(10 \mu \mathrm{g}$ meropenem or imipenem) adsorbed with $100 \mathrm{mM}$ EDTA. ${ }^{11}$ Control disks containing only carbapenem were used to evaluate the enlargement of inhibitory zones attributed to the EDTA effect. Specific primers were used in standard polymerase chain reactions (PCR) to detect the following carbapenemase genes: $b_{\mathrm{KPC}}(\mathrm{F}, 5$ 'TGTCACTGTATCGCCGTC and $\left.\mathrm{R}, \quad 5^{\circ} \mathrm{CTCAGTGCTCTACAGAAAACC}\right),{ }^{12}$

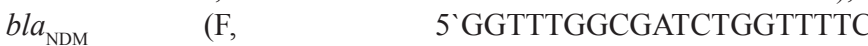
and $\mathrm{R}, \quad 5$ GGCCTTGCTGTCCTTGATC), $b l a_{\mathrm{IMP}}$ (F1, CATTTCCATAGCGACAGCAC; 5'AACACGGTTTGGTGGTTCTT and 5 GGACTTTGGCCAAGCTTCTA), 5'CTCGATGAGAGTCCTTCTAGAG) and bla $a_{\mathrm{OXA}-48}$ (F, 5 GCGTGGTTAAGGATGAACAC and R, 5 ATCATCAAGTTCAACCCAACC). The primers used for amplification of $b l a_{\mathrm{NDM}}, b l a_{\mathrm{IMP}}, b l a_{\mathrm{VIM}}$ and $b l a_{\mathrm{OXA}-48}$ were described in this study. PCR products were submitted to DNA sequencing (ABI 3130 Genetic Analyzer- Applied Biosystems ${ }^{\circledR}$ ) in order to confirm the identity of the amplified genes. Clonal relatedness among isolates was examined by Random Amplified Polymorphic DNA (RAPD) performed with the primer OPA-2 (5'TGCCGAGCTG) (Operon Technologies, Alameda, CA, USA).$^{13}$ The band patterns were analyzed by visual interpretation, applying the criteria established by Belkum et al. ${ }^{14}$ In addition, RAPD patterns were analyzed and dendograms were built employing PyElph software system (version 2.6.5). ${ }^{15}$

\section{Results and discussion}

Among Enterotacteriaceae strains reported to the Public Health Laboratory (LACEN-DF) in Brazil, K. pneumonia was the most frequently CRE detected $(\mathrm{n}=61 / 88 ; 69.3 \%)$, followed by species of Enterobacter $(\mathrm{n}=15 / 88 ; 17.1 \%)$.

The emergence of CRE species has increased the demand on old or outdated antibiotics. ${ }^{16}$ In this scenario, the increasing interest on colistin (polymyxin) as an evaluable treatment has driven the emergence of species intrinsically resistant to colistin including Proteuss spp., Serratia spp., Morganella spp. and Providencia spp. ${ }^{17}$ In our study, intrinsically colistin-resistant strains accounted for $9.0 \%$ of the CRE isolates and they included $S$. marcescens $(\mathrm{n}=4 / 88 ; 4.5 \%)$, P. mirabilis $(\mathrm{n}=3 / 88 ; 3.4 \%)$ and . rettgeri $(\mathrm{n}=1 / 88 ; 1.1 \%)$.

In relation to carbapenemase genes, $b l a_{\mathrm{KPC}}$ was the most frequently detected gene in the tested CRE strains ( $\mathrm{n}=59 / 88 ; 67.0 \%)$, followed by $b l a_{\mathrm{NDM}}(\mathrm{n}=7 / 88 ; 8.0 \%)$. Additionally, carbapenemase genes with minor epidemiological relevance were also tested $\left(b l a_{\mathrm{VIM}}, b l a_{\mathrm{IMP}}\right.$ and $\left.b l a_{\mathrm{OXA}-48}\right)$, but they were not detected among the CRE isolates. Focusing on NDM genes, we firstly isolated a $b l a_{\mathrm{NDM}}$-positive $P$. rettgeri strain from a necrotic ulcer affecting a 75 -year-old male patient in May 2013. The patient had received treatment in two hospitals, both located in Brasília, and had not reported travelling abroad in the six previous years. The $P$. rettgeri strain showed in vitro resistance to all tested antimicrobial agents with the exception of gentamicin. The sequence analysis (Basic Local Alignment Search Tool) of the $b l a_{\mathrm{NDM}}$ amplicon showed an identity of $100 \%$ (435/435 base-pairs) with previous reported $b l a_{\mathrm{NDM}-1}$ genes (GeneBank Number: KJ150691.1). Additionally, two distinct bands of plasmid DNA were found in the $P$. rettgeri strain (data not shown). PCR assays carried out with purified plasmid DNA showed that $b l a_{\mathrm{NDM}-1}$ gene was located on the highmolecular-weight plasmid (molecular weight $>50 \mathrm{~Kb}$ ). Interesting, Carvalho-Assef et al. ${ }^{8}$ also recovered a NDM-producing P. rettgeri strain from a diabetic foot infection in early 2013, but differently the $b l a_{\mathrm{NDM}-1}$ gene was chromosomally integrated.

Thereafter the first detection of $b l a_{\mathrm{NDM}}$, six other $b l a_{\mathrm{NDM}}$-positive strains (K. pneumonia, $\mathrm{n}=4 ;$ P. mirabilis, $\mathrm{n}=1 ; E$. coli, $\mathrm{n}=1$ ) were isolated in three hospitals. All isolates were resistant to $\beta$-lactams (with exception of aztreonam and cefotetan), quinolones, nitrofurantoin and trimethoprim-sulfamethoxazole; and showed variable susceptibility profiles against aminoglycosides, tetracycline and tigecycline (Table 1). Interesting, all NDM-producing strains showed negative results for the carbapenemase expression assay MHT. However, NDM-producing strains are positive in the EDTA test confirming the production of metallo- $\beta$-lactamases (Table 1). Negative or weakly positive results in MHT have been already reported for NDM-producing strains. ${ }^{18}$ However, these findings are worrisome once phenotypic detection of carbapenemase in MHT is recommended for the clinical microbiology laboratories as epidemiological screening assay for detection of CRE isolates. ${ }^{10}$

Four strains of NDM-producing K. pneumoniae were isolated from patients treated in three hospitals; therefore, it was tested if these strains were clonally unrelated as commonly reported for $b l a_{\mathrm{NDM}}$-positive strains. ${ }^{19-21}$ However, all NDM-producing $K$. pneumoniae strains tested in this study were considered as genetically indistinguishable on RAPD analyses, showing the same amplified polymorphic DNA pattern (Figure 1B \& 1C). Two of these strains were isolated from two patients (patients 2 and 3) assisted in the same hospital (hospital B), warning for the possibility of cross infections (Table $1 \&$ Figure 1). The other two clonal strains of $K$. pneumoniae were isolated from two patients (patients 5 and 6) treated in two different hospitals (hospital $\mathrm{C}$ and D) (Table 1 \& Figure 1). Moreover, because of a prolonged colonization period ( 2 months and 10 days) with $b l a_{\mathrm{NDM}}$-positive strains (K. pneumoniae and $E$. coli), the patient 6 had the opportunity of translocating two NDM-producing enterobacterial species into two different hospitals (Table 1). Additionally, the isolation of different bacterial species positive for $b a_{\mathrm{NDM}}$ from the patient 6 (Table 1) endorses the idea on the promiscuous nature of mobile genetic elements carrying $b l a_{\text {NDM }}$ genes. ${ }^{3}$ These findings reinforce the role of patient transfer in spreading NDM-producing bacteria among hospitals, ${ }^{22}$ and endorses the need of rapid communication that alerts about the presence of infected or colonized patients with NDMproducing strains in Brazil hospitals.

As occurs in Brasília, Brazilian hospitals have frequently reported outbreaks involving CRE strains mainly associated with $b l a_{\mathrm{KPC}^{-}}$ positive $K$. pneumoniae strains belonging to the clonal complex 258 (ST 11) ${ }^{23,24}$ The clone ST11 of $K$. pneumoniae has been characterized for causing large outbreaks, ${ }^{25}$ and has been also responsible for spreading $b l a_{\mathrm{NDM}}$ gene in Greece. ${ }^{26}$ Taken together, these data warn about the possibility of a worst-case scenario, in which, the epidemic clone ST11 would acquire the $b l a_{\mathrm{NDM}}$ gene and spread among Brazilian hospital. 
Table I NDM-producing strains isolated in Brasília hospitals

\begin{tabular}{|c|c|c|c|c|c|c|c|}
\hline \multirow[b]{2}{*}{ Patient } & \multirow[b]{2}{*}{ Species } & \multirow[b]{2}{*}{$\begin{array}{l}\text { Susceptible } \\
\text { phenotype }^{\text {a }}\end{array}$} & \multirow[b]{2}{*}{ Hospitals } & \multirow[b]{2}{*}{$\begin{array}{l}\text { Isolation } \\
\text { Date }\end{array}$} & \multicolumn{3}{|c|}{ Assays for carbapenemase detection } \\
\hline & & & & & $\begin{array}{c}\text { Phenotypic } \\
\text { assay for } \\
\text { carbapenemase } \\
\text { (MHT) }\end{array}$ & $\begin{array}{l}\text { Phenotypic } \\
\text { assay for } \\
\text { metallo- } \beta- \\
\text { lactamase } \\
\text { (EDTA test) }\end{array}$ & $\begin{array}{c}\text { PCR for } \\
\text { bla }_{\text {NDM }}\end{array}$ \\
\hline I & Providencia rettgeri & GEN,TET & A & $03 / 06 / 2013$ & Negative & Positive & Positive \\
\hline 2 & Klebsiella pneumoniae & $\begin{array}{c}\text { AMI,AZT,TET, } \\
\text { TGN }\end{array}$ & B & $20 / 08 / 2013$ & Negative & Positive & Positive \\
\hline 3 & Klebsiella pneumoniae & AMI,TGN & B & $07 / 09 / 2013$ & Negative & Positive & Positive \\
\hline 4 & Proteus mirabilis & $\begin{array}{c}\text { AMI, CTE, GEN, } \\
\text { TOB, }\end{array}$ & B & $30 / 10 / 2013$ & Negative & Positive & Positive \\
\hline 5 & Klebsiella pneumoniae & AMI,TGN & $\mathrm{C}$ & $3 / 11 / 2013$ & Negative & Positive & Positive \\
\hline 6 & Klebsiella pneumoniae & $\begin{array}{c}\text { AMI,AZT,TET, } \\
\text { TGN }\end{array}$ & $\mathrm{D}$ & $11 / 11 / 2013$ & Negative & Positive & Positive \\
\hline 6 & Escherichia coli & $\begin{array}{c}\text { AMI,AZT, GEN, } \\
\text { NIT,TGN }\end{array}$ & $E$ & $2 \mathrm{I} / 0 \mathrm{I} / 20 \mathrm{I}$ & Negative & Positive & Positive \\
\hline
\end{tabular}

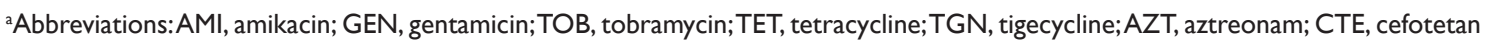


a)

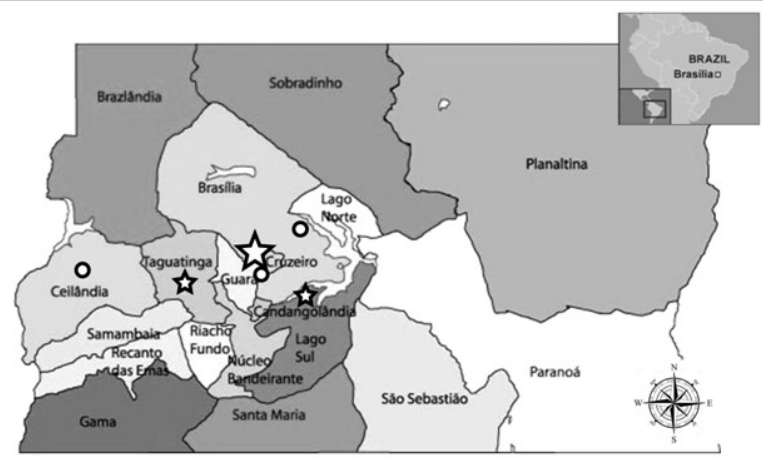

b)

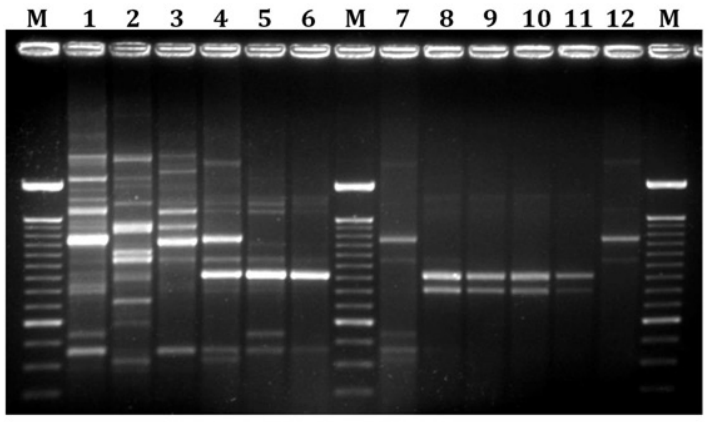

c)

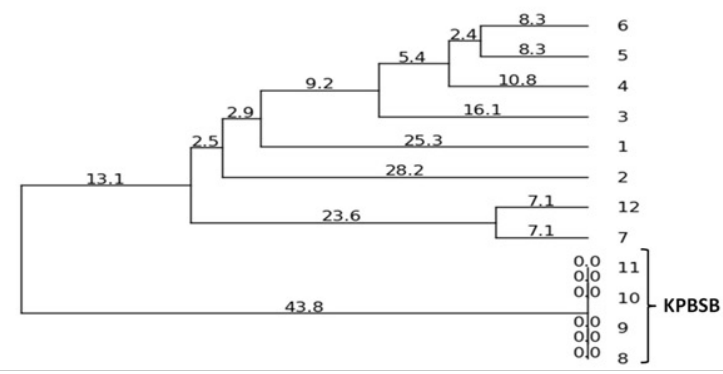

Figure 1 Distribution of cases of NDM-producing Enterobacteriaceae strains in Brasília and genetic relatedness of $b l a_{\mathrm{NDM}}$-producing $K$. pneumoniae strains. A) Geographic distribution of the occurrence of NDM-producing strains. Symbols: Stars correspond to the cases associated with bla $a_{\mathrm{NDM}}$-positive $K$. pneumoniae (small star - 1 case; large star - 2 cases). Circles indicate cases associated with other bla $a_{\mathrm{NDM}}$-positive strains (Providencia rettgeri, $P$. mirabilis and Escherichia coli). B) RAPD profiles of the carbapenem-resitant $K$. pneumoniae strains. bla $a_{\mathrm{NDM}}$-positive $K$. pneumoniae showed the same RAPD profile (samples 8-11) and were named KPBSB clone. Sample 1, K. pneumoniae IOC4955; sample 2, K. pneumoniae ATCC700603; samples 3 to 7 and 12 bla $a_{\mathrm{KPC}}$-positive strains isolated in different hospitals in Brasília (enrolled to examine the discriminatory power of the RAPD assay); samples 8 and 9, bla $a_{\mathrm{NDM}}$-positive strains isolated in hospital B; sample 10, bla $a_{\mathrm{NDM}}$-positive strain isolated in hospital D; and, sample 11, bla ${ }_{\mathrm{NDM}}$-positive strain isolated in hospital C. C) Dendrogram of the RAPD profiles as analyzed with PyElph software system (version 2.6.5). (see description of figure 1B for sample consultation).

\section{Conclusion}

Hospitals in Brazil have reported the isolation of several species of CRE positive for $b l a_{\mathrm{KPC}}$, and, more recently, for $b l a_{\mathrm{NDM}}$ as well Additionally, the initial spread of $b l a_{\mathrm{NDM}}$-positive $K$. pneumoniae strains has been driven by a single clone. Our findings suggest that bla ${ }_{\mathrm{NDM}}$-positive strains are been transported among hospitals by inpatient transfers and that they are spreading throughout patient cross infections. Finally, the present results call for an improved surveillance on inpatient transfers, for the molecular detection of CRE strains, and for enforcements in infection control measures.

\section{Conflict of interest}

All authors declare to have no conflict of interest.

\section{Acknowledgement}

Brasília Study Group on Bacterial Resistance: Alessandra Peres Pinheiro Domingues, Alessandra Reis Moreira, Brenda Paula PiresSousa, Eli Mendes Ferreira, Leonardo Borges Ferreira, Luana A A Martins, Melissa Jordão Sacramento, Michelle Capucci Martins. This work was supported by Fundação de Apoio à Pesquisa do Distrito Federal (Grant numbers: 193.000.019/2012, 2010/00188-1, 563981/2010-5), Conselho Nacional de Desenvolvimento Científico e Tecnológico (Grant number 301156/2011-5) and Coordenação de Aperfeiçoamento de Nível Superior (Grant number 001-2009).

\section{References}

1. Nordmann P, Dortet L, Poirel L. Carbapenem resistance in Enterobacteriaceae: here is the storm! Trends Mol Med. 2012;18(5):263-272.

2. Nordmann P, Cuzon G, Naas T. The real threat of Klebsiella pneumoniae carbapenemase-producing bacteria. Lancet Infect Dis. 2009;9(4):228-236.

3. Nordmann P, Poirel L, Walsh TR, et al. The emerging NDM carbapenemases. Trends Microbiol. 2011;19(12):588-595.

4. Queenan AM, Bush K. Carbapenemases: the versatile beta-lactamases. Clin Microbiol Rev. 2007;20(3):440-458.

5. Yong D, Toleman MA, Giske CG, et al. Characterization of a new metallo-beta-lactamase gene, bla(NDM-1), and a novel erythromycin esterase gene carried on a unique genetic structure in Klebsiella pneumoniae sequence type 14 from India. Antimicrob Agents Chemother. 2009;53(12):5046-5054.

6. Walsh TR, Weeks J, Livermore DM, et al. Dissemination of NDM-1 positive bacteria in the New Delhi environment and its implications for human health: an environmental point prevalence study. Lancet Infect Dis. 2011;11(5):355-362.

7. Johnson AP, Woodford N. Global spread of antibiotic resistance: the example of New Delhi metallo- $\beta$-lactamase (NDM)-mediated carbapenem resistance. J Med Microbiol. 2013;62(Pt 4):499-513.

8. Carvalho-Assef AP, Pereira PS, Albano RM, et al. Isolation of NDMproducing Providencia rettgeri in Brazil. $J$ Antimicrob Chemother. 2013;68(12):2956-2957

9. Bonelli RR, Moreira BM, Picão RC. Antimicrobial resistance among Enterobacteriaceae in South America: history, current dissemination status and associated socioeconomic factors. Drug Resist Updat. 2014;17(1-2):24-36

10. CLSI. Performance Standards for Antimicrobial Susceptibility Testing; Twenty-Fourth Informational Supplement n.d.:CLSI document M100-S24. Clinical and La, Wayne, PA, USA. 2014.

11. Nordmann P, Poirel L, Carrër A, et al. How to detect NDM-1 producers. J Clin Microbiol. 2011;49(2):718-721. 
12. Yigit H, Queenan AM, Anderson GJ, et al. Novel carbapenemhydrolyzing beta-lactamase, KPC-1, from a carbapenem-resistant strain of Klebsiella pneumoniae. Antimicrob Agents Chemother. 2001;45(4):1151-1161.

13. Abou-Dobara MI, Deyab MA, Elsawy EM, et al. Antibiotic susceptibility and genotype patterns of Escherichia coli, Klebsiella pneumoniae and Pseudomonas aeruginosa isolated from urinary tract infected patients. Polish J Microbiol. 2010;59(3):207-212.

14. van Belkum A, Tassios PT, Dijkshoorn L, et al. Guidelines for the validation and application of typing methods for use in bacterial epidemiology. Clin Microbiol Infect. 2007;13(Suppl 3):1-46.

15. Pavel AB, Vasile CI. PyElph - a software tool for gel images analysis and phylogenetics. BMC Bioinformatics. 2012;13:9.

16. Kanj SS, Kanafani ZA. Current Concepts in Antimicrobial Therapy Against Resistant Gram-Negative Organisms: Extended-Spectrum $\beta$-Lactamase-Producing Enterobacteriaceae, Carbapenem-Resistant Enterobacteriaceae, and Multidrug-Resistant Pseudomonas aeruginosa. Mayo Clin Proc. 2011;86(3):250-259.

17. Kontopidou F, Plachouras D, Papadomichelakis E, et al. Colonization and infection by colistin-resistant Gram-negative bacteria in a cohort of critically ill patients. Clin Microbiol Infect. 2011;17(11):E9-E11.

18. Castanheira M, Deshpande LM, Mathai D, et al. Early dissemination of NDM-1- and OXA-181-producing Enterobacteriaceae in Indian hospitals: report from the SENTRY Antimicrobial Surveillance Program, 2006-2007. Antimicrob Agents Chemother 2011;55(3):1274-1278.

19. Nordmann P, Naas T, Poirel L. Global spread of Carbapenemase-producing Enterobacteriaceae. Emerg Infect Dis. 2011;17(10):1791-1798.
20. Nordmann P, Poirel L, Toleman MA, et al. Does broad-spectrum betalactam resistance due to NDM-1 herald the end of the antibiotic era for treatment of infections caused by Gram-negative bacteria? J Antimicrob Chemother. 2011;66(4):689-692.

21. Kumarasamy KK, Toleman MA, Walsh TR, et al. Emergence of a new antibiotic resistance mechanism in India, Pakistan, and the UK: a molecular, biological, and epidemiological study. Lancet Infect Dis. 2010;10(9):597-602.

22. van der Bij AK, Pitout JDD. The role of international travel in the worldwide spread of multiresistant Enterobacteriaceae. $J$ Antimicrob Chemother. 2012;67(9):2090-2100.

23. Pereira PS, de Araujo CF, Seki LM, et al. Update of the molecular epidemiology of KPC-2-producing Klebsiella pneumoniae in Brazil: spread of clonal complex 11 (ST11, ST437 and ST340). J Antimicrob Chemother. 2013;68(2):312-316.

24. Nicoletti AG, Fehlberg LC, Picao RC, et al. Clonal Complex 258, the Most Frequently Found Multilocus Sequence Type Complex in KPC2-Producing Klebsiella pneumoniae Isolated in Brazilian Hospitals. Antimicrob Agents Chemother. 2012;56(8):4563-4564.

25. Chmelnitsky I, Shklyar M, Hermesh O, et al. Unique genes identified in the epidemic extremely drug-resistant KPC-producing Klebsiella pneumoniae sequence type 258. J Antimicrob Chemother. 2013;68(1):74-83

26. Voulgari E, Gartzonika C, Vrioni G, et al. The Balkan region: NDM-1producing Klebsiella pneumoniae ST11 clonal strain causing outbreaks in Greece. J Antimicrob Chemother. 2014;69(8):2091-2097. 